IJIS Indonesian Journal on Information System

\title{
RANCANG BANGUN GAME EDUKASI BERBASIS WEB DAN ANDROID MENGGUNAKAN ADOBE FLASH CS5 DAN ACTION SCRIPT 3.0
}

\section{ARCHITECTURE WEB-BASED EDUCATIONAL GAME and ANDROID USING ADOBE FLASH CS5 and ACTION SCRIPT 3.0}

\author{
Winda Angela Hamka ${ }^{1}$, Abdu Gani ${ }^{2}$ \\ Program Studi Teknik Komputer, \\ Politeknik Sains dan Teknologi Wiratama Maluku Utara \\ winda.angela.hamka@gmail.com
}

\begin{abstract}
Abstrak
Media merupakan salah satu bagian dari sistem pembelajaran. Oleh karena itu adanya media sangat berpengaruh terhadap jalannya proses pembelajaran. Dengan adanya media dalam proses pembelajaran akan mempermudah anak atau siswa memahami hal yang dipelajari, salah satunya dengan menerapkan game edukasi dan diperkenalkan melalui media pembelajaran game yang berbasis web dan smartphone dalam bahasa daerah, Sistem yang dirancang menggunakan Adobe Flash Cs5 dan Action Script 3.0 Android Air Plugin for Adobe Flash Cs5 sebagai pembantu pembuatan script pada Android yang disajikan dalam bahasa daerah yaitu bahasa Ternate sehingga dapat Mengembangkan kecerdasan kreativitas anak terutama dalam mengembangkan bahasa daerah dikota Ternate, dengan adanya sistem ini diharapkan dapat Mengembangkan kecerdasan kreativitas anak, yang tadinya dengan cara belajar konvensional menjadi cara belajar simulasi Sebagai media alternatif untuk pembelajaran dengan game edukasi yang di sajikan dalam bahasa daerah yaitu bahasa ternate
\end{abstract} Kata Kunci : Game Edukasi, Web, Android

\begin{abstract}
The media is one part of the learning system. Therefore the existence of a highly influential media against the course of the learning process. With the presence of the media in the process of learning will facilitate the child or students understand things that were studied, one of them by applying educational games and introduced through the medium of learning web-based games and smartphones in regional language, The system is designed using Adobe Flash Cs5 and Action Script 3.0 Android Air Plugin for Adobe Flash Cs5 as an auxiliary script creation on Android that is presented in the local language of Ternate so that it can Develop the intelligence of children's creativity especially in developing the local language in the city of Ternate, in the presence of the system is expected to Develop children's creativity, intelligence, who had become the conventional way of learning with learning simulations As alternative media for learning with educational games that are presented in the local language which is the language ternate
\end{abstract}

Keyword: Educational Games, Web, Android

\section{PENDAHULUAN}

Media merupakan salah satu bagian dari sistem pembelajaran. Oleh karena itu adanya media sangat berpengaruh sekali terhadap jalannya proses pembelajaran. Dengan adanya media dalam proses pembelajaran akan mempermudah siswa memahami hal yang dipelajari. 
Salah satu media pendidikan adalah penerapan game atau disebut game edukasi. Bermula dari perkembangan video game yang sangat pesat dan menjadikannya media alternatif untuk kegiatan pembelajaran. Suasmoro mengungkapkan, game edukasi ini perlu dikembangkan dan tidak seharusnya game tidak hanya menyenangkan tapi juga mendidik (Republika,2011).

Dengan kecanggihan teknlogi jaman sekarang, ada baiknya game mampu berjalan di atas dua platform yang berbeda, baik melalui smarthphone maupun PC, dengan cara online ataupun offline. Smartphone adalah salah satu teknologi mutakhir di mana ia mampu melakukan tugas-tugas lain disamping menelpon dan SMS, tapi juga sebagai perangkat komputasi dan hiburan dalam ukuran genggaman yang memudahkan pemakainya, begitupula saat bermain game. Umumnya sebuah smartphone sudah dibekali dengan sistem operasi contohnya Android.

Menurut Henry (2010), game adalah aktifitas yang melibatkan satu atau lebih pemain. Game dapat pula diartikan sebagai tujuan yang ingin dicapai pemain atau sekumpulan aturan yang menandakan apa yang dilakukan pemain dan yang tidak dapat dilakukan. Game dimainkan terutama untuk hiburan, kesenangan, tetapi dapat juga berfungsi sebagai sarana latihan, pendidikan dan simulasi. Dalam game terdapat berbagai macam model permainan yang disajikan oleh beberapa pembuat baik dalam negeri maupun diluar negeri salah satunya adalah model game edukasi untuk anak

Kesuksesan suatu game juga dipengaruhi cara mengenalkannya kepada publik, dan internet adalah salah satu solusinya. Perkembangan internet dapat menghilangkan hambatan, jarak, waktu dan ruang sehingga dapat membantu penyerapan informasi dan komunikasi. Ditambah penggunanya yang besar dan semakin berkembang, internet bisa menjadi tolak ukur agar game terus berevolusi dari masukan dengan masuknya tanggapan penggunanya

Untuk mengembangkan kecerdasan anak salah satu diperkenalkan melalui media pembelajaran game yang berbasis web dan smartphone dengan adanya media game untuk usia dini dapat Mengembangkan kecerdasan kreativitas anak, yang tadinya dengan cara belajar konvensional menjadi cara belajar simulasi Sebagai media alternatif untuk pembelajaran dengan game edukasi

\section{Rumusan Masalah}

Berdasarkan latar belakang yang telah disampaikan maka dapat dirumuskan masalah, yaitu: Bagaimana merancang game melalui Adobe Flash Cs5 dan Action Script 3.0 penelitian ini di batasi yaitu Aplikasi game digunakan pada Android 2.3 Gingerbread dan Ice Cream Sandwich versi terakhir, Game yang dibuat hanya membahas mengenai permainan untuk anak usia dini yang mana permainannya hanya berupa game sederhana yaitu mencocokkan warna dengan bahasa daerah yaitu bahasa Ternate sehingga dapat Mengembangkan kecerdasan kreativitas anak terutama dalam mengembangkan bahasa daerah dikota Ternate, Sebagai media alternatif untuk pembelajaran dengan game edukasi yang di sajikan dalam bahasa daerah yaitu bahasa ternate

\section{LANDASAN TEORI \\ Pengertian Game}

Game adalah kata berbahasa Inggris yang berarti permainan atau pertandingan, 
atau bisa diartikan sebagai aktifitas terstruktur yang biasanya dilakukan untuk bersenang-senang. Menurut Anggra (Zulfadli Fahrul Rozi, 2010:6) game atau permainan adalah sesuatu yang dapat dimainkan dengan aturan tertentu sehingga ada yang menang dan ada yang kalah, biasanya dalam konteks tidak serius dengan tujuan refreshing. Macam-macam game, antara lain:

a. Aksi

Genre ini merupakan macam game yang paling popular. Game jenis ini membutuhkan kemampuan reflex pemain. Salah satu subgenre action yang popular adalah First Person Shooter (FPS). Pada game FPS diperlukan kecepatan berfikir. Game ini dibuat seolah-olah pemain yang berada dalam suasana tersebut. Pemain dalam game ini diberi keleluasaan untuk membangun dan suatu proyek tertentu dengan bahan baku yang terbatas.

b. Role Playing Games (RPG)

Dalam RPG pemain dapat memilih satu karakter untuk dimainkan. Seiring dengan naiknya level game, karakter tersebut dapat berubah, bertambah kemampuannya, bertambah senjatanya, atau bertambah hewan peliharaannya.

c. Strategi

Genre strategi menitikberatkan pada kemampuan pada kemampuan berpikir dan organisasi. Game strategi dibedakan menjadi dua, yaitu Turn Based Strategy dan Real Time Strategy. Jika real time strategi mengharuskan pemain membuat keputusan dan secara bersamaan pihak lawan juga beraksi hingga menimbulkan serangkaian kejadian dalam waktu yang sebenarnya, sedangkan turn based strategi pemain bergantian menjalankan taktiknya. Saat pemain mengambil langkah, pihak lawan menunggu. Demikian juga sebaliknya.

d. Balapan

Pemain dapat memilih kendaraan, lalu melaju di arena balap. Tujuannya yaitu mencapai garis finish tercepat.

e. Olahraga

Genre ini membawa olahraga ke dalam sebuah komputer atau konsol. Biasanya gameplay dibuat semirip mungkin dengan kondisi olahraga yang sebenarnya.

f. Puzzle

Genre puzzle menyajikan teka-teki, menyamakan warna bola, perhitungan matematika, menyusun balok, atau mengenal huruf dan gambar.

g. Permainan Kata

Word game sering dirancang untuk menguji kemampuan dengan bahasa atau untuk mengeksplorasi sifatsifatnya. Word Game umumnya digunakan sebagai sumber hiburan, tetapi telah dibuktikan untuk melayani suatu tujuan pendidikan juga. Berdasarkan uraian di atas dapat disimpulkan game adalah suatu hasil dari proses multimedia berupa alat untuk bersenang senang dan dapat digunakan sebagai media untuk pembelajaran

\section{Elemen Dasar Game}

Menurut Dillon (dalam Puput, 2005) elemen-elemen dasar sebuah game adalah :

1. Games Rule

Games rule merupakan aturan perintah, cara menjalankan, fungsi objek dan karakter di dunia permainan dunia game. Dunia game bisa berupa pulau, dunia khayal dan tempat-tempat 
sejenis yang dipakai sebagai set tempat dalam permainan game.

2. Plot

Plot biasanya berisi informasi tentang hal - hal yang akan dilakukan oleh pemain dalam game dan secara detail tentang perintah atau hal yang harus dicapai dalam game.

3. Tema

Di dalam biasanya terdapat pesan moral yang ingin disampaikan.

4. Karakter

Pemain sebagai karakter utama maupun karakter lain yang memiliki sifat tertentu.

5. Objek

Merupakan sebuah hal penting dan biasanya digunakan pemain untuk memecahkan masalah, adakalanya pemain harus punya keahlian dan pengetahuan untuk bisa memainkannya.

6. Teks, Grafik dan Suara

Game biasanya merupakan kombinasi dari media teks, grafik, maupun suara, walaupun tidak harus semuanya ada dalam permainan game.

7. Animasi

Animasi ini selalu melekat pada dunia game, khususnya untuk gerakan karakter - karakter yang ada dalam game

8. User Interface

Merupakan fitur - fitur yang mengkomunikasikan pemain dengan game.

\section{Pengertian Edukasi}

Dalam kamus besar bahasa Inggris education berarti pendidikan,sedangkan menurut Sugihartono (2007:3) pendidikan berasal dari kata didik, atau mendidik yang berarti memelihara dan membentuk latihan Edukasi (Kamus Besar Bahasa Indonesia
Edisi Keempat, 2008) ialah yang berhubungan dengan pendidikan. Pendidikan diartikan sebagai proses pengubahan sikap dan tata laku seseorang atau sekelompok orang dalam usaha mendewasakan manusia melalui upaya pengajaran dan pelatihan. Pendidikan adalah sebuah proses pembelajaran yang didapat oleh setiap manusia, dalam hal ini adalah peserta didik, tujuannya adalah untuk membuat peserta didik itu paham, mengerti serta mampu berpikir lebih kritis. Pendidikan adalah sebuah proses pembelajaran yang didapat oleh setiap manusia, dalam hal ini adalah peserta didik, tujuannya adalah untuk membuat peserta didik itu paham, mengerti serta mampu berpikir lebih kritis.

\section{Pengertian Game Edukasi}

Game yang memiliki konten pendidikan lebih dikenal dengan istilah game edukasi. Game berjenis edukasi ini bertujuan untuk memancing minat belajar anak terhadap materi pelajaran sambil bermain, sehingga pemain diharapkan bisa lebih mudah memahami materi pelajaran yang disajikan. Jenis ini sebenarnya lebih mengacu kepada isi dan tujuan game, bukan jenis sesungguhnya (Henry, 2010).

\section{Pengertian Web}

Menurut Tim EMS (2012) secara terminologi, website adalah kumpulan dari halaman - halaman situs yang terangkum dalam sebuah domain atau sub domain yang tempatnya berada di dalam World Wide Web disebut juga sebagai WWW di dalam internet. Sebuah halaman web biasanya berupa dokumen dengan format HTML (Hyper Text Markup Languange) bisa diakses melalui HTTP, yaitu suatu protokol penyampaian informasi dari server website untuk ditampilkan kepada 
para pemakai melalui web browser. Semua publikasi dari website tersebut dapat membentuk sebuah jaringan informasi yang sangat besar

\section{Pengertian Android}

Menurut Safaat (2012) Android adalah sistem operasi menggunakan Linux yang dirancang untuk perangkat seluler seperti telepon pintar (smartphone) dan komputer tablet. Android awalnya dikembangkan oleh Android, Inc.. dengan dukungan finansial dari Google yang kemudian membelinya pada tahun 2005.

Android ialah sistem operasi dengan sumber terbuka, dan Google merilis kodenya di bawah lisensi apache. Kode dengan lisensi terbuka dalam lisensi perizinan Android memungkinkan perangkat lunak ini untuk dimodifikasi secara bebas dan didistribusikan oleh pembuat perangkat, operator nirkabel dan pengembang aplikasi. Selain itu, Android memiliki sejumlah besar komunitas pengembang aplikasi (apps) yang memperluas fungsionalitas perangkat.

\section{Pengertian Adobe Flash}

Adobe System adalah perusahaan perangkat lunak yang bergerak di bidang grafis, animasi, video, dan perkembangan web. Adobe adalah salah satu perusahaan perangkat lunak yang paling besar di dunia. Perusahaan ini didirikan pada tahun 1982 dan berpusat di San Jose, California, AS. Adobe Flash merupakan sebuah program yang didesain khusus oleh Adobe dan program aplikasi standar Authoring Tool Profesional yang digunakan untuk membuat animasi dan bitmap yang sangat menarik untuk keperluan situs web yang interaktif maupun dinamis (Radion, 2012).

\section{Pengertian Action Script}

ActionScript adalah bahasa pemrograman yang dibuat berdasarkan ECMA Script, digunakan dalam pengembangan situs web dan perangkat lunak menggunakan platform Adobe Flash Player (Radion, 2012). Actionscript merupakan suatu programming language (bahasa pemrograman) yang dapat ditambahkan pada dokumen Flash (baik itu pada frame, movie clip, atau button) untuk dapat membuat suatu animasi yang lebih interaktif. Seperti halnya pada pemrograman $\mathrm{C}, \mathrm{C}++$ dan Java, Action Script memiliki sifat yang sangat sensitif (case-sensitive) artinya penulisan huruf sangat berpengaruh.

\section{METODE PENELITIAN Metode Pengembangan Sistem}

Metode pendekatan dalam pengembangan sistem yang digunakan dalam peneliti ialah pada metode water fall. Metode water fall adalah salah satu model pengembangan, dimana kemajuan suatu proses terus mengalir ke bawah seperti air terjun. Dengan menggunakan pendekatan metode ini proses rekayasa perangkat lunak disusun melalui beberapa tahapan dapat dilihat pada gambar sebagai berikut:

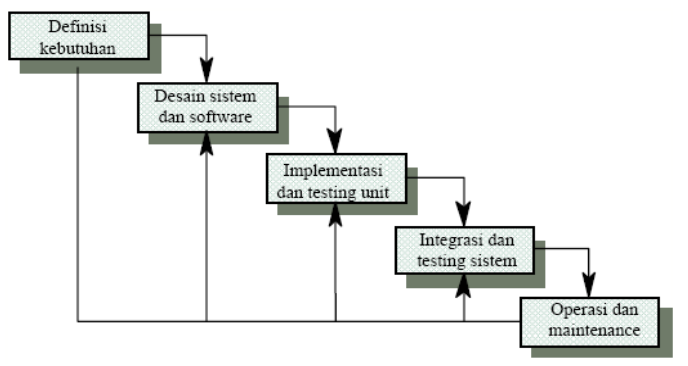

Gambar 1 : Metode Pengembangan water fall.

Sumber: Dyta, 2001.

Tahapan-tahapan yang harus dilaksanakan adalah sebagai berikut

1. Definisi Kebutuhan 
Mengumpulkan kebutuhan secara lengkap kemudian dianalisis dan didefinisikan kebutuhan yang harus dipenuhi oleh program yang akan dibangun. Fase ini harus dikerjakan secara lengkap untuk bisa menghasilkan desain yang lengkap.

2. Desain Sistem dan Software

Desain dikerjakan setelah kebutuhan selesai dikumpulkan secara lengkap. Dan dirancang dalam bentuk diagram sistem

3. Implementasi dan Testing Unit

Desain program diterjemahkan ke dalam kode - kode dengan menggunakan bahasa pemrograman yang sudah ditentukan

4. Integrasi Dan Testing Sistem

Penyatuan unit - unit program kemudian diuji secara keseluruhan (system testing).

5. Operasi dan Maintenance

Mengoperasikan program dilingkungannya dan melakukan pemeliharaan, seperti penyesuaian atau perubahan karena adaptasi dengan situasi sebenarnya

\section{Analisa sistem yang berjalan}

Analisa sistem yang berjalan merupakan desain alur kerja sistem yang masih bersifat konvensional, Berikut merupakan tampilan alur kerja sistem yang berjalan yang di tampilkan pada Flowchart system dapat dilihat pada gambar sebagai berikut:



Gambar 2 : Flowchart Sistem Yang Berjalan

\section{Rancangan system yang di usulkan}

Rancangan Sistem yang di usulkan merupakan sistem yang baru dapat di tampilkan pada gambar flowchart Sebagai berikut:

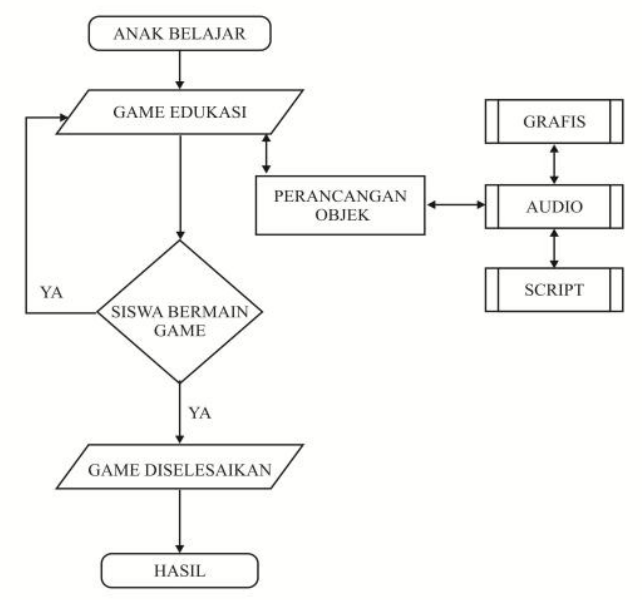

Gambar 3 : Flowchart Rancangan Sistem Yang Diusulkan

\section{Alat dan bahan penelitian}

Untuk merancang game maka peneliti memakai alat- alat di bawah ini

\section{Software}

a. Windows Seven Home Premium

b. Adobe Flash Cs5 Sebagai media pembuatan game

c. Action Script 3.0 sebagai kode pembuatan script 
d. Android Air Plugin for Adobe Flash Cs5 sebagai pembantu pembuatan script pada Android

e. Adobe Air for Android penyelia antara file apk Adobe Flash agar mampu dibaca Android

f. Android Gingerbread 2.3.1

g. Jet Audio

h. Google Chrome

\section{Hardware}

a. Notebook dengan prosesor AMD Radeon

b. Motherboard

c. RAM

d. Hardisk

e. Optical Mouse

f. Kartu grafis

g. Keyboard

h. Headset PC Sennheiser Communication

i. Smartphoe Sony Erricson Xperia Ray

j. Smartphone Cross

k. Samsung Galaxy Tablet

\section{PERANCANGAN SISTEM}

Game sendiri terdiri dari 3 pilar utama yaitu grafis, sound dan script yang akan diolah melalui Adobe Flash Cs5 dan bantuan Action Script 3.0. Untuk membantu mempermudah produksi dan menampilkan game edukasi ini, penyusun menuangkannya kedalam sebuah bagan sebagai berikut



Gambar 4 : Tampilan Bagan Produksi

\section{Rancangan Logo}

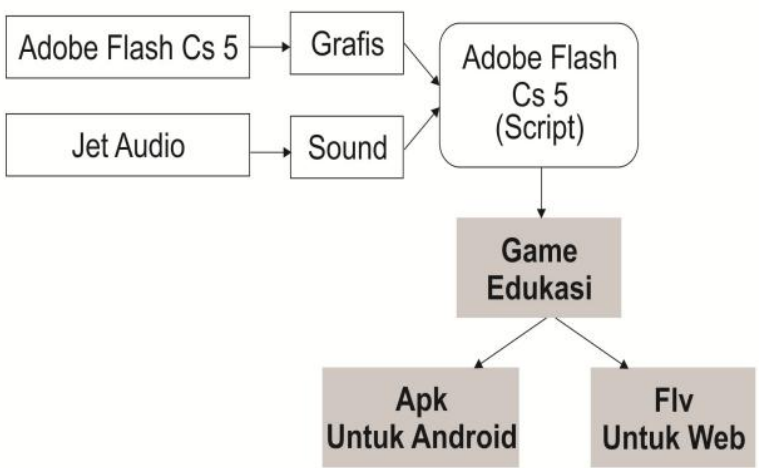

Gambar 5 : Tampilan Logo

\section{Rancangan Ikon}
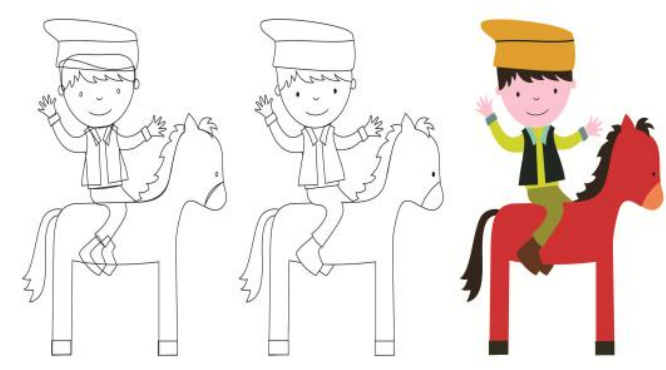

Gambar 6 : Rancangan Ikon



Gambar 7 : Rancangan Buah



Gambar 8: Rancangan Keranjang 


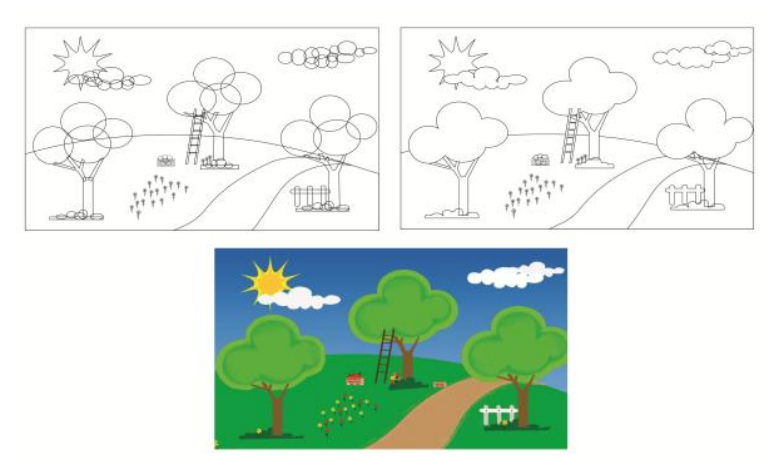

Gambar 9: Rancangan Latar

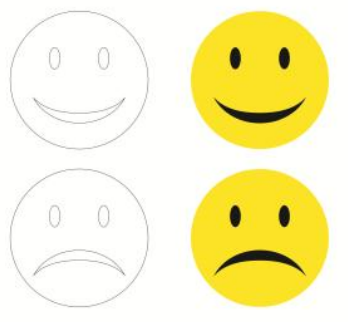

Gambar 10: Rancangan Icon Hasil

\section{Tabel Pengaturan Properti Game Pembuka}

Table 1 : Properti Game Pembuka

\begin{tabular}{|c|c|l|l|}
\hline No & Objek & Property & Setting \\
\hline 1 & Opening & $\begin{array}{l}\text { Name } \\
\text { Layer }\end{array}$ & $\begin{array}{l}\text { Opening.flv } \\
\text { Opening }\end{array}$ \\
\hline 2 & Ikon & $\begin{array}{l}\text { Name } \\
\text { Layer }\end{array}$ & $\begin{array}{l}\text { Ikon.flv } \\
\text { Opening }\end{array}$ \\
\hline 3 & Logo & $\begin{array}{l}\text { Name } \\
\text { Layer }\end{array}$ & $\begin{array}{l}\text { Logo.flv } \\
\text { Opening }\end{array}$ \\
\hline 4 & Mulaeng & $\begin{array}{l}\text { Name } \\
\text { Layer } \\
\text { Type } \\
\text { Instance Name }\end{array}$ & $\begin{array}{l}\text { btn_play } \\
\text { opening } \\
\text { Button } \\
\text { btn_play }\end{array}$ \\
\hline
\end{tabular}

Tabel Pengaturan Properti Memulai Game

Table 2 : Properti Game memulai Game

\begin{tabular}{|c|l|l|l|}
\hline No & Objek & \multicolumn{1}{|c|}{ Property } & \multicolumn{1}{c|}{ Setting } \\
\hline 1 & Enviro & $\begin{array}{l}\text { Name } \\
\text { Layer }\end{array}$ & $\begin{array}{l}\text { Enviro.flv } \\
\text { Back }\end{array}$ \\
\hline 2 & Logo & Logo & Logo.flv \\
\hline
\end{tabular}

\begin{tabular}{|c|c|c|c|}
\hline & & Layer & Back \\
\hline 3 & $\begin{array}{l}\text { Buah } \\
\text { mangga }\end{array}$ & $\begin{array}{l}\text { Name } \\
\text { Layer } \\
\text { Type } \\
\text { Instance } \\
\text { Name }\end{array}$ & $\begin{array}{l}\text { drop1 } \\
\text { buah dan } \\
\text { keranjang } \\
\text { Movie Clip } \\
\text { drop1_mc }\end{array}$ \\
\hline 4 & $\begin{array}{l}\text { Buah } \\
\text { mangga }\end{array}$ & $\begin{array}{l}\text { Name } \\
\text { Layer } \\
\text { Type } \\
\text { Instance } \\
\text { Name }\end{array}$ & $\begin{array}{l}\text { drop1 } \\
\text { buah dan } \\
\text { keranjang } \\
\text { Movie Clip } \\
\text { drop11_mc }\end{array}$ \\
\hline 5 & $\begin{array}{l}\text { Buah } \\
\text { mangga }\end{array}$ & $\begin{array}{l}\text { Name } \\
\text { Layer } \\
\text { Type } \\
\text { Instance } \\
\text { Name }\end{array}$ & $\begin{array}{l}\text { drop1 } \\
\text { buah dan } \\
\text { keranjang } \\
\text { Movie Clip } \\
\text { drop111_mc }\end{array}$ \\
\hline 6 & $\begin{array}{l}\text { Buah } \\
\text { mangga }\end{array}$ & $\begin{array}{l}\text { Name } \\
\text { Layer } \\
\text { Type } \\
\text { Instance } \\
\text { Name }\end{array}$ & $\begin{array}{l}\text { drop1 } \\
\text { buah dan } \\
\text { keranjang } \\
\text { Movie Clip } \\
\text { drop1111_mc }\end{array}$ \\
\hline 7 & Buah apel & $\begin{array}{l}\text { Name } \\
\text { Layer } \\
\text { Type } \\
\text { Instance } \\
\text { Name }\end{array}$ & $\begin{array}{l}\text { drop2 } \\
\text { buah dan } \\
\text { keranjang } \\
\text { Movie Clip } \\
\text { drop2_mc }\end{array}$ \\
\hline 8 & Buah apel & $\begin{array}{l}\text { Name } \\
\text { Layer } \\
\text { Type } \\
\text { Instance } \\
\text { Name } \\
\end{array}$ & $\begin{array}{l}\text { drop2 } \\
\text { buah dan } \\
\text { keranjang } \\
\text { Movie Clip } \\
\text { drop22_mc }\end{array}$ \\
\hline 9 & Buah apel & $\begin{array}{l}\text { Name } \\
\text { Layer } \\
\text { Type } \\
\text { Instance } \\
\text { Name }\end{array}$ & $\begin{array}{l}\text { drop2 } \\
\text { buah dan } \\
\text { keranjang } \\
\text { Movie Clip } \\
\text { drop222_mc }\end{array}$ \\
\hline 10 & Buah apel & $\begin{array}{l}\text { Name } \\
\text { Layer } \\
\text { Type } \\
\text { Instance } \\
\text { Name }\end{array}$ & $\begin{array}{l}\text { drop2 } \\
\text { buah dan } \\
\text { keranjang } \\
\text { Movie Clip } \\
\text { drop2222_mc }\end{array}$ \\
\hline 11 & Buah pear & $\begin{array}{l}\text { Name } \\
\text { Layer } \\
\text { Type } \\
\text { Instance } \\
\text { Name }\end{array}$ & $\begin{array}{l}\text { drop3 } \\
\text { buah dan } \\
\text { keranjang } \\
\text { Movie Clip } \\
\text { drop3_mc }\end{array}$ \\
\hline 12 & Buah pear & $\begin{array}{l}\text { Name } \\
\text { Layer } \\
\text { Type } \\
\text { Instance } \\
\text { Name }\end{array}$ & $\begin{array}{l}\text { drop3 } \\
\text { buah dan } \\
\text { keranjang } \\
\text { Movie Clip } \\
\text { Drop33_mc }\end{array}$ \\
\hline 13 & Buah pear & $\begin{array}{l}\text { Name } \\
\text { Layer } \\
\text { Type } \\
\text { Instance } \\
\text { Name }\end{array}$ & $\begin{array}{l}\text { drop3 } \\
\text { buah dan } \\
\text { keranjang } \\
\text { Movie Clip } \\
\text { drop333_mc }\end{array}$ \\
\hline 14 & Buah pear & $\begin{array}{l}\text { Name } \\
\text { Layer } \\
\text { Type } \\
\text { Instance }\end{array}$ & $\begin{array}{l}\text { drop3 } \\
\text { buah dan } \\
\text { keranjang } \\
\text { Movie Clip }\end{array}$ \\
\hline
\end{tabular}

Volume 1 Nomor 2 | September 2016 


\begin{tabular}{|c|c|c|c|}
\hline & & Name & drop3333_mc \\
\hline 15 & $\begin{array}{l}\text { Keranjang } \\
\text { hijau }\end{array}$ & $\begin{array}{l}\text { Name } \\
\text { Layer } \\
\text { Type } \\
\text { Instance } \\
\text { Name }\end{array}$ & $\begin{array}{l}\text { hitTarget1 } \\
\text { buah dan } \\
\text { keranjang } \\
\text { Movie Clip } \\
\text { dropZone1_mc }\end{array}$ \\
\hline 16 & $\begin{array}{l}\text { Keranjang } \\
\text { merah }\end{array}$ & $\begin{array}{l}\text { Name } \\
\text { Layer } \\
\text { Type } \\
\text { Instance } \\
\text { Name }\end{array}$ & $\begin{array}{l}\text { hitTarget2 } \\
\text { buah dan } \\
\text { keranjang } \\
\text { Movie Clip } \\
\text { dropZone2_mc }\end{array}$ \\
\hline 17 & $\begin{array}{l}\text { Keranjang } \\
\text { kuning }\end{array}$ & $\begin{array}{l}\text { Name } \\
\text { Layer } \\
\text { Type } \\
\text { Instance } \\
\text { Name }\end{array}$ & $\begin{array}{l}\text { hitTarget3 } \\
\text { buah dan } \\
\text { keranjang } \\
\text { Movie Clip } \\
\text { dropZone3_mc }\end{array}$ \\
\hline 18 & Ulang & $\begin{array}{l}\text { Name } \\
\text { Layer } \\
\text { Type } \\
\text { Instance } \\
\text { Name }\end{array}$ & $\begin{array}{l}\text { Reset } \\
\text { reset } \\
\text { Button } \\
\text { reset_btn }\end{array}$ \\
\hline 19 & Moi Rai & $\begin{array}{l}\text { Name } \\
\text { Layer } \\
\text { Type } \\
\text { Instance } \\
\text { Name }\end{array}$ & $\begin{array}{l}\text { done_btn } \\
\text { reset } \\
\text { Button } \\
\text { done_btn }\end{array}$ \\
\hline 20 & Ijo & $\begin{array}{l}\text { Name } \\
\text { Linkage }\end{array}$ & $\begin{array}{l}\text { ijo.wav } \\
\text { ijo }\end{array}$ \\
\hline 21 & Ruriha & $\begin{array}{l}\text { Name } \\
\text { Linkage }\end{array}$ & $\begin{array}{l}\text { ruriha.wav } \\
\text { ruriha }\end{array}$ \\
\hline 22 & Kuraci & $\begin{array}{l}\text { Name } \\
\text { Linkage }\end{array}$ & $\begin{array}{l}\text { kuraci.wav } \\
\text { kuraci }\end{array}$ \\
\hline 23 & $\begin{array}{l}\text { Ikon } \\
\text { Bahagia }\end{array}$ & $\begin{array}{l}\text { Name } \\
\text { Layer } \\
\text { Type } \\
\text { Instance } \\
\text { Name }\end{array}$ & $\begin{array}{l}\text { right_mc } \\
\text { result } \\
\text { Movie Clip } \\
\text { rigth_mc }\end{array}$ \\
\hline 24 & $\begin{array}{l}\text { Ikon } \\
\text { Sedih }\end{array}$ & $\begin{array}{l}\text { Name } \\
\text { Layer } \\
\text { Type } \\
\text { Instance } \\
\text { Name }\end{array}$ & $\begin{array}{l}\text { wrong_mc } \\
\text { result } \\
\text { Movie Clip } \\
\text { wrong_mc }\end{array}$ \\
\hline
\end{tabular}



Gambar 11 : Desain publikasi versi web

\section{Publikasi Untuk Versi Android}

Sama dengan versi web, dalam penggunaan dalam versi android game harus dikonversi dari fla menjadi file apk. File apk adalah file yang bisa dibaca Android. Terlebih dahulu perangkat Android diinstal Adobe Air for Android yang bisa didapatkan di Android appstore, ini berfungsi sebagai penyelia antar file apk dari fla dengan sistem di Android, berikut merupakan tampilan halaman desain publikasi untuk versi android dalam sistem dapat disajikan dalam gambar sebagai berikut:
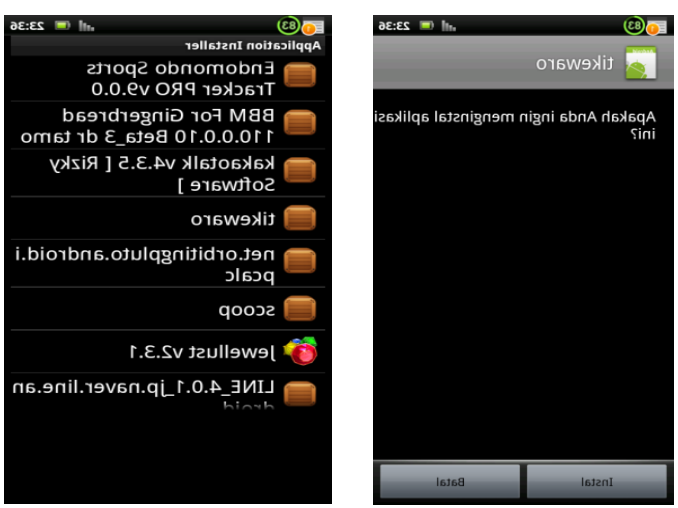

Gambar 12 : Desain publikasi versi Android 1 



Gambar 13 : Desain publikasi versi Android 2

\section{IMPLEMENTASI SISTEM}

\section{Tampilan Game Pembuka}



Gambar 14: Rancangan Icon Hasil Tampilan Pembuka

\section{Tampilan Memulai Permainan}

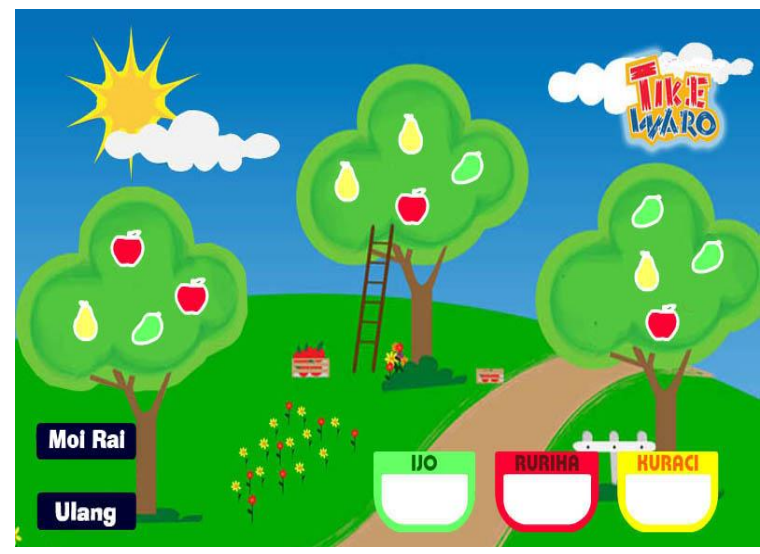

Gambar 15: Tampilan Memulai Permainan

\section{KESIMPULAN}

Dari hasil Perancangan dan Implementasi Game Edukasi Berbasis Web dan Android menggunakan Adobe flash Cs 5 dan Action Script 3.0 adalah : dapat Mengembangkan kecerdasan kreativitas anak terutama dalam mengembangkan bahasa daerah dikota Ternate, karena dalam game edukasi memiliki unsur tantangan, ketepatan dan etika dan Mengubah cara belajar konvensional menjadi cara belajar simulasi Sebagai media alternatif untuk pembelajaran dengan game edukasi yang di sajikan dalam bahasa daerah yaitu bahasa ternate

Berdasarkan kesimpulan di atas, maka diajukan saran sebagai berikut.: Sistem yang dibuat dapat digunakan sebagai simulasi untuk media alternatif untuk pembelajaran dengan game edukasi, Kedepan sistem yang dibuat bisa digunakan disemua kalangan usia anak. Game Edukasi yang dirancang masih belum sempurna Peneliti berharap untuk pengembangan berikut agar sistem bisa di kembangkan pada jenjang android yang lebih baru dan sistem yang dijalankan secara berjenjang agar dapat memberikan edukasi yang lebih baik pada perkembangan anak

\section{DAFTAR PUSTAKA}

Madcoms.2012. Kupas Tuntas Adobe Flash Professional Cs6. Andi Offset: Yogyakarta

Radion, Krito.2012. Easy Game Programming Using Flash and Action Scrip 3.0. Andi Offset: Yogyakarta

Safaat, Nazruddin. Pemrograman Aplikasi Mobile Smartphone dan Tablet PC Berbasis Android. Informatika Bandung, Bandung 
Sugono, Dendy. dkk.2008. Kamus Besar Bahasa Indonesia Edisi Keempat. Balai Pustaka: Jakarta

Tim EMS.2012. Web Programming for Beginners: Elex Media Komputindo: Jakarta

Wahana Komputer. 2012. Panduan Aplikasi dan Solusi (PAS) Beragam Desain Game Edukasi dengan Adobe Flash Cs5. Andi Offset: Yogyakarta

Dedy Sugiarto, Cicilia Puji Rahayu, Pembuatan Program Permainan Petualangan Tom Menggunakan Visual Basic 6.0, Indonesian Jurnal on Computer Science - Speed (IJCSS) 13 Vol 9 No 2 - Agustus 2012, ISSN $1979-9330$

Bangun Wijayanto, S.T., M.Cs, Prototype Aplikasi Tumbuh Kembang Balita Berbasiskan Android Untuk kader Posyandu Di Pedesaan, Seminar Nasional Aplikasi Teknologi Informasi 2012 (SNATI 2012), ISSN: 1907-5022

Wahyu Wibisono, Lies Yulianto, Perancangan Game Edukasi Untuk Media Pembelajaran Pada Sekolah Menengah Pertama Persatuan Guru Republik Indonesia Gondang Kecamatan Nawangan Kabupaten Pacitan, Indonesian Jurnal on Computer Science - Speed (IJCSS) 13 Vol 9 No 2 - Agustus 2012, ISSN $1979-9330$

Yogi Siswanto, Bambang Eka Purnama, Rancang Bangun Aplikasi Mobile Game Edukasi Ilmu Pengetahuan Alam Untuk Anak Kelas VI Sekolah Dasar, Journal Speed - Sentra Penelitian Engineering dan Edukasi Volume 5 No 4 - 2013, ISSN : 1979-9330 (Print) - 2088-0154 (Online)
Surati, Strategi Pembangunan Game Edukasi Berbasis Desktop Untuk Anak Usia 4-6 Tahun, Jurnal Speed Vol 11 No 1 - 2014, ISSN 1979 9330

Putri Intan Sari, Bambang Eka Purnama, Game Edukasi Mata Pelajaran Ilmu Pengetahuan Alam (IPA) Dan Ilmu Pengetahuan Sosial (IPS) Pada Sekolah Dasar Negeri Sooka I Punung Kabupaten Pacitan, Journal Speed - Sentra Penelitian Engineering dan Edukasi - Volume 7 No 1 - 2015, ISSN : 1979-9330 (Print) - 2088-0154 (Online) 